\title{
A ATUAÇÃO PROFISSIONAL DOS EGRESSOS COMO IMPORTANTE DIMENSÃO NO PRO- CESSO DE AVALIAÇÃO DE PROGRAMAS DE PÓS-GRADUAÇÃo
}

\author{
The alumni's professional positioning as an unequivocally way in order \\ to evaluate the post graduation program
}

Sílvia Aparecida Guarnieri Ortigoza

Profa. Dra. no Depto. de Geografia - IGCE, UNESP, Rio Claro sago@rc.unesp.br

Ligia Celoria Poltroniéri-

Profa. Dra. Aposentada, Depto. de Geografia - IGCE, UNESP, Rio Claro cpligiaonline@hotmail.com

Lucy Marion C. Philadelpho MachadoProfa. Dra. Aposentada, Depto. de Geografia - IGCE, UNESP, Rio Claro lucy-machado@hotmail.com

Artigo recebido em 07/08/2011 e aceito para publicação em 17/07/2012

RESUMO: A análise do quadro geral da inserção profissional dos egressos é uma forma inequívoca para avaliação de Programas de Pós-Graduação no que tange à qualidade de sua formação e preparo de profissionais gabaritados para o mercado de trabalho. Este artigo relata a experiência pioneira do Programa de Pós-Graduação em Geografia- UNESP/ Rio Claro (SP) na construção de instrumentos de avaliação a partir da procedência, formação acadêmica e destino profissional dos egressos, nos níveis de Mestrado e Doutorado, no período de 1980-2008. Os resultados foram resumidos em gráficos e mapas e são elementos importantes para mostrar o desenvolvimento e a disseminação da ciência geográfica no Brasil e no exterior. A metodologia utilizada revelou-se extremamente eficaz, podendo ser utilizada por qualquer Programa, com as devidas adaptações, para avaliar tanto sua realidade quando sua extensão.

Palavras-chave: egressos, pós-graduação, metodologia de análise, destino profissional

ABSTRACT: The analysis of the results about the alumni's professional positioning is an unequivocally way in order to evaluate the post graduation program regarding to quality of their background and the grooming of qualified professionals for a niche market. The purpose of this research is reporting a groundbreaking experience of the Post Graduation Program in Geography - UNESP/ Rio Claro - SP by framing criteria concerning the alumni's origin, academic background and their current position, in both Master Degree and PHD, between 1980-2008. The outcome have been summarized and placed into graphs and maps, becoming key element regarding to development and spreading the Geography science in Brazil and also abroad. The methodology which has been applied revealed to be extremely efficient, which could taken by any other Program, nevertheless taking its differences into consideration, in order to evaluate its reality as well as its range.

Key words: alumini, post graduation, analysis methodology, professional destiny. 


\section{INTRODUÇ̃̃̃O}

A CAPES tem manifestado a importância da atuação profissional dos egressos de Programas de Pós-Graduação como importante instrumento a ser considerado no processo de avaliação. Para tanto, tem deixado, a critério de cada Programa, a decisão sobre a forma de realizar uma análise coerente da atuação de seus egressos. O propósito é identificar o local, a Instituição de atuação profissional dos egressos, e suas posições (cargos, chefias) uma vez que a análise do quadro geral da inserção profissional dos egressos é uma forma inequívoca de avaliar o Programa no que tange à qualidade de sua formação e preparo de profissionais gabaritados para o mercado especializado de trabalho.

Assim, este artigo apresenta as estratégias encontradas no triênio 2007-2009 pelo Conselho do Programa de Pós-Graduação em Geografia- Área de Concentração em Organização do Espaço da UNESP, Campus de Rio Claro, para dar maior atenção aos egressos do Programa, com vistas a contribuir para uma avaliação mais completa da qualidade e extensão do mesmo.

O objetivo deste artigo é relatar a experiência do Programa de Pós-Graduação em Geografia da UNESP de Rio Claro na construção de instrumentos de avaliação a partir da procedência, formação acadêmica e destino profissional dos egressos do Programa. Essa ampliação da análise permitiu avaliar, de fato, o verdadeiro progresso científico de cada ex-aluno, revelado através de sua inserção profissional.

Tendo em vista a exigüidade de tempo para apresentação dos resultados no Relatório Trienal do Programa (2007-2009), o período analisado foi determinado pelo ano em que ocorreu a primeira Defesa de Dissertação de Mestrado até o ano anterior ao da coleta dos dados, ou seja, de 1980 a 2008, considerando todas as Dissertações e Teses defendidas. O período de coleta, tratamento e análise das informações ocorreu de abril a novembro de 2009 .

Os resultados do levantamento sobre os egressos do Programa no período 1980-2008, foram plenamente suficientes para uma exata avaliação quantitativa da importância da Pós- Graduação em Geografia de Rio Claro, no cenário brasileiro, além de identificar aspectos relevantes da formação profissional adquirida com a titulação.

\section{O PROGRAMA DE PÓS-GRADUAÇÃO EM GEOGRAFIA DA UNESP DE RIO CLARO (SP) NO CONTEXTO DA PÓS-GRADUAÇÃO NA- CIONAL}

O Programa de Pós-Graduação em GeografiaÁrea de Concentração em Organização do Espaço instalou-se em 1976, no Instituto de Geociências e Ciências Exatas (IGCE) da UNESP, Campus de Rio Claro e as atividades acadêmicas tiveram início em 1977, em nível de Mestrado e, em 1983, em nível de Doutorado.

Neste período, o Programa propiciou a formação de inúmeros pesquisadores que atuam, também, como professores de Universidades Públicas, Estaduais e Federais, bem como em Instituições privadas, tanto no nível de Graduação quanto de Pós-Graduação. Trata-se, portanto, de um Programa consolidado no contexto da Pós-Graduação brasileira e, em especial, no campo da ciência geográfica.

Desde o início das atividades, em 1977, até dezembro de 2008, portanto durante 31 anos, foram defendidos 480 trabalhos de pesquisa sendo 317 Dissertações de Mestrado e 163 Teses de Doutorado. Em 2008 eram alunos regulares do Programa: 57 mestrandos e 71 doutorandos enquanto que o corpo docente credenciado, no mesmo ano, contava com 25 docentes permanentes e 08 docentes colaboradores.

Em todos estes anos de atividade, o Programa apresentou um crescimento necessário e compatível com momentos em que poucos eram os Programas de Pós-Graduação em Geografia existentes e grande era a demanda brasileira por vagas. Hoje, o panorama nacional é outro tendo em vista a abertura de inúmeros outros Programas nas várias regiões do país.

Nem por isso, entretanto, o Programa de Pós-Graduação em Geografia da UNESP de Rio Claro deixou de ser procurado.

Deve-se ressaltar também que este Programa, de forma pioneira, sempre procurou atender à demanda de formação, principalmente dos estados do nordeste, do sul e do norte do país, através de Convênios com a Universidade Federal de Sergipe, Universidade

Soc. \& Nat., Uberlândia, ano 24 n. 2, 243-254, mai/ago. 2012 
Federal de Santa Maria e, mais recentemente, com o Instituto Federal de Educação Ciência e Tecnologia do Piauí- IFPI e Instituto Federal de Educação, Ciência e Tecnologia do Ceará- IFCE, ambos em andamento a partir de 2008.

Entretanto, durante os 31 anos de existência do Programa, em nenhum momento foi dada especial atenção aos egressos, isto é, não havia nenhum levantamento sobre a procedência dos alunos que o procuravam em busca de titulação, seu perfil acadêmico (área de formação) e, muito menos, sobre o destino profissional dos Mestres e Doutores por ele formados.

$\mathrm{O}$ que havia, até o momento, eram as informações anotadas, de forma resumida, pelos próprios pós-graduandos no momento da inscrição dados estes, que permaneciam registrados nos arquivos da Seção de Pós-Graduação do IGCE, UNESP/RC, sem qualquer análise.

Para que se tenha maior compreensão da magnitude desta pesquisa, o universo de trabalho foi composto pelo número total de defesas ocorridas no período 1980-2008, tanto de Dissertações de Mestrado (317) como de Teses de Doutorado (163).

Deste total, descontou-se 76 egressos que obtiveram, no Programa, tanto o título de Mestre como o de Doutor em Geografia. Assim, das 480 defesas, o universo de pesquisa reduziu-se para 404 egressos.

Neste contexto, o objetivo do levantamento foi pesquisar, quantitativamente, os egressos do Programa quanto à: procedência, área de atuação profissional pós-titulação e local de trabalho.

Considerando-se o grande número de pessoas envolvidas e a exigüidade de tempo disponível para a realização da pesquisa (abril a novembro de 2009) definiram-se formas e estratégias pelas quais tal objetivo pudesse ser alcançado, tendo-se plena consciência de que a análise qualitativa não faria parte deste primeiro levantamento, devendo ser objeto de nova pesquisa.

\section{PROCEDIMENTOS METODOLÓGICOS}

Um ponto de extrema importância para a realização desta pesquisa foi o acesso a artigos que relatavam experiências de sistema de avaliação de cursos. Essa etapa significou conhecer o universo avaliativo de diferentes cursos o que permitiu que se pudesse antever diversos problemas que poderiam surgir no desenvolvimento do estudo.

$\mathrm{O}$ artigo de Cunha et al (2007) revelou uma preocupação de um grupo de professores que buscava apresentar algumas dimensões que foram definidas para a avaliação e a construção de instrumentos para analisar: a) o perfil dos ingressantes, b) a avaliação dos cursos pelos alunos e c) a investigação da situação dos egressos. "A tarefa de avaliar é, portanto, complexa. Nunca se consegue abranger todos os aspectos que merecem ser avaliados e compatibilizá-los com o tamanho dos instrumentos é importante para que possa haver adesão dos alunos." (CUNHA et al, 2007,p. 37)

Para os Cursos de Pós-graduação lato sensu a rotina da avaliação fez-se necessária já há algum tempo; para os cursos stritu sensu estas questões aparecem de forma mais contundente e global e de modo mais exigente nas últimas duas décadas, consolidando-se neste novo século. Desse modo, os desafios ainda estão postos, e mesmo para aqueles que já estão mais acostumados com a rotina avaliativa, novas e consecutivas estratégias de análise estarão sempre presentes.

O cenário global do mercado de trabalho apresenta uma competitividade bastante acirrada e os profissionais devem sempre ampliar suas competências e qualificações, buscando diferenciais. Assim, a formação continuada é o caminho que vem sendo incentivado para o acúmulo de novos conhecimentos.

Falar da educação na perspectiva do futuro é, pois, tarefa cheia de riscos, mas importante. Não é irrelevante pensar que fomos educados para um mundo que não existe mais e estamos educando as novas gerações para um mundo que muito brevemente será outro. Num mundo de tantas e velozes mudanças, a escola tem permanecido praticamente a mesma. Quase não nos damos conta de que nossos alunos estariam sendo hoje preparados para postos ou funções que muito em breve estarão modificados, exigindo diferentes capacitações, ou até mesmo serão simplesmente extintos. Não nos apercebemos hoje que boa parte dos conhecimentos que ensinamos já está ultrapassada no momento mesmo do ensino ou se tornará obsoleta em poucos anos. Não temos 
A atuação profissional dos egressos como importante dimensão no processo de avaliação de programas de pós-graduação Sílvia Aparecida Guarnieri Ortigoza, Lígia Celoria Poltroniéri , Lucy Marion C. Philadelpho Machado

muita clareza sobre quantas novas profissões surgiram e quantas outras aparecerão em breve. (DIAS SOBRINHO, 2000, p. 20).

Outro aspecto importante no processo avaliativo decorre da avaliação do Programa por parte dos egressos. Trata-se ainda, de um novo desafio, uma vez que eles são capazes de analisar de forma melhor e mais abrangente, até que ponto a carga horária, os conteúdos, enfim, as estratégias de formação estão sendo de fato importantes para que a atuação profissional seja a mais eficaz possível. Não se trata de preparar apenas para o mercado de trabalho, e sim conjugar várias dimensões para que o egresso possa, a partir de seu desempenho, demonstrar sempre a importância da "Escola" onde foi formado.

Assim, avaliar cursos e programas, tendo como elemento norteador da qualidade do que se produz nesses cursos, no seio da universidade, implica considerar as várias comunidades de referência que interagem com a universidade: a cientifica, a pedagógica (ligada aos processos formativos), a do trabalho, as civis, etc., que não são consideradas nos momentos de avaliação, em que, na maioria das vezes, se acumulam dados que não recebem a devida atenção como elementos importantes para mudanças, que permitem avanços socioeducacionais e culturais. (CUNHA apud GATTI, 2007, p. 31).

No âmbito da Geografia foram vários os geógrafos que realizaram estudos procurando retratar uma visão mais geral do perfil da Pós-Graduação em Geografia no Brasil. Entre esses autores destacam-se: GERARDI (2003), DUARTE (2003), CARLOS (2003) SUERTEGARAY (2003, 2005 e 2007), SILVA, e DANTAS, (2005), MENDONÇA (2005) e SILVA e OLIVEIRA (2009). Entretanto, vale destacar que a análise dos egressos nunca havia sido contemplada nem quantitativa, nem qualitativamente.

Suertegaray, (2007) traçou um panorama geral ao analisar 29 Cursos de Pós-Graduação em Geografia, mas o foco de seu trabalho concentrou-se na produção de Teses e Dissertações.
Para fazer esta análise, avaliou-se, a partir da produção de teses e dissertações dos 29 programas distribuídos em território nacional, alguns elementos que podem indicar, através do título do trabalho, atualidade e tendências. Para tanto, levantei duas dimensões que norteiam minhas preocupações: a escala de análise e os subcampos da Geografia. Considerando a escala, classifiquei os trabalhos nas escalas local, regional, nacional e abrangência internacional. A definição dos campos temáticos (sub-unidades da Geografia) não foi feita a priori, resultou da análise do conjunto de dissertações e teses, portanto, constitui elemento de indicação de tendência. Observei, para o conjunto dos dados, temas relativos à Geografia Física, Geografia Humana, Ambiente, Educação e Geografia, Teoria e Método em Geografia. (SUERTEGARAY, p. 26, 2007)

Em vista do exposto, fica comprovada a importância da realização desta pesquisa que buscou, de forma inédita, caminhos para a análise quantitativa dos egressos de Programas de Pós-Graduação a partir de um estudo de caso.

A coleta das informações foi realizada, concomitantemente, de várias formas:

a) consulta aos documentos fornecidos, no momento da inscrição e arquivados na Seção de Pós-Graduação do IGCE-UNESP/RC. Foram considerados apenas os dados relativos aos pós-graduandos que, efetivamente, defenderam Dissertações e ou Teses, tais como: Instituição de conclusão da Graduação; área acadêmica de formação e ano de conclusão; endereço postal e telefônico; endereço eletrônico para os mais recentes;

b) contato com os Orientadores para obter informações sobre atuais e ex-orientandos;

c) pesquisa na Plataforma LATTES visando à complementação dos dados, quando necessário;

d) envio de mensagens eletrônicas solicitando as informações pendentes;

e) outras formas de localização utilizadas para contatar um reduzidíssimo número de egressos: contatos telefônicos ou via parentes, amigos e conhecidos;

Soc. \& Nat., Uberlândia, ano 24 n. 2, 243-254, mai/ago. 2012 
envio de correspondência da Coordenação, via postal. Ressalte-se que este recurso foi utilizado para tentar localizar apenas 10 egressos, com 3 cartas devolvidas pelo não encontro do destinatário; informações obtidas através de colegas de turma, funcionários da Pós-Graduação e outras pessoas sobre o atual local de moradia e ou de trabalho dos egressos.

Todas as informações coletadas foram inseridas em planilhas considerando o total de defesas ocorridas ano a ano, em cada um dos níveis: Mestrado e Doutorado. Nestas planilhas foram reunidas as seguintes informações: ano da defesa, nome do egresso, Instituição de Graduação, Instituição de atuação profissional, cidade, estado e outras informações tais como: se na ativa, aposentado, desempregado, falecido, cursando Doutorado ou Pós-Doutorado no Brasil ou no exterior, dentre outras.

A etapa seguinte foi resumir os dados contidos nas planilhas em gráficos e mapas, tanto para o Mestrado como para o Doutorado, com o objetivo de facilitar a leitura e a compreensão dos dados relativos à procedência dos egressos e às áreas de atuação profissional.

A construção de mapas, também para os dois níveis, revelou a espacialização do destino profissional dos egressos do Programa de Pós-Graduação em Geografia- Área de Concentração em Organização do Espaço, da UNESP, Campus de Rio Claro.
Em outra etapa, os resultados foram analisados nos dois níveis (Mestrado e Doutorado) considerando-se: a procedência dos alunos por região geográfica, as áreas de atuação profissional com todas as especificidades determinadas pelo levantamento $\mathrm{e}$ a espacialização do destino profissional de cada um dos 404 egressos.

\section{EGRESSOS DO MESTRADO}

O período analisado foi de 28 anos (19802008) considerando o total de 317 egressos no nível de Mestrado.

Dos alunos que procuraram o Programa para cursar o Mestrado, no período 1980-2008, 44\% (140) eram formados no Curso de Geografia da UNESP de Rio Claro.

$\mathrm{O}$ restante dos alunos eram procedentes de todas as regiões do Brasil, principalmente das regiões Sudeste (27\%), Sul (16\%), Nordeste (5\%), Centro-Oeste (3\%) e Norte (2\%).

O Programa recebeu, também, alunos estrangeiros provenientes da América Latina: Chile (3), Peru (1), Argentina (1),Colômbia (1) e Cuba (1) e do continente africano: Moçambique (1), totalizando $3 \%$. Na Figura 1 é possível visualizar as várias categorias de análise e respectivas porcentagens.

Figura 1. Procedência dos egressos do mestrado do Programa de Pós-graduação em Geografia da UNESP Rio Claro - Período 1980-2008

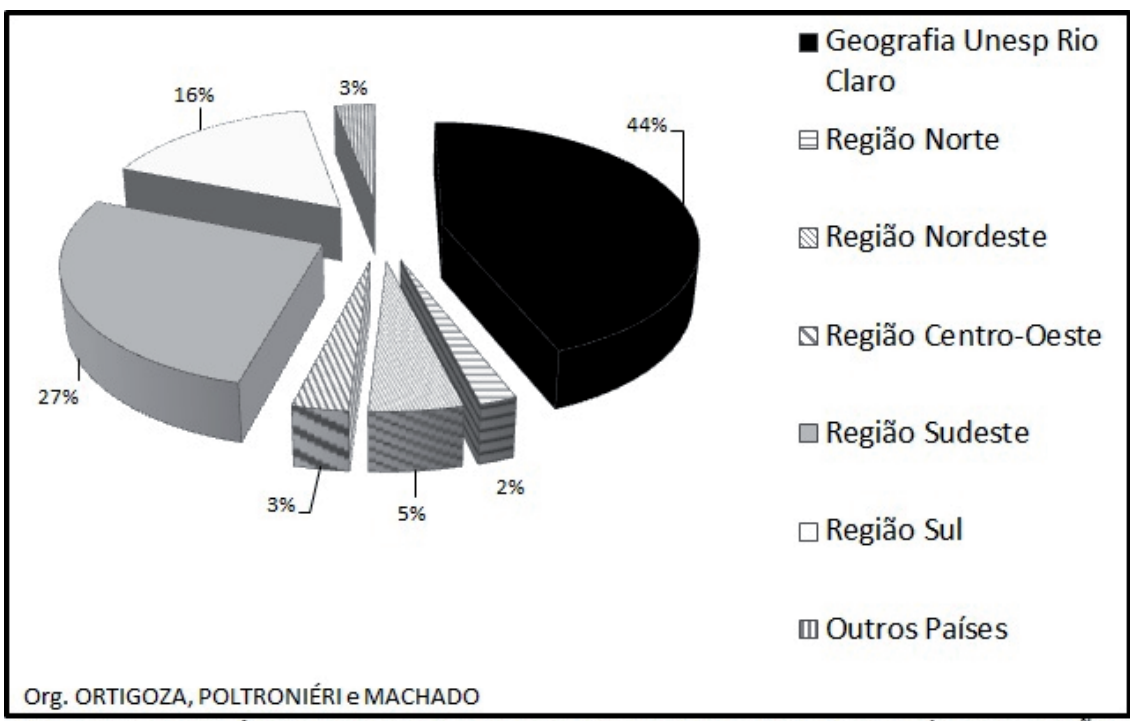

Soc. \& Nat., Uberlândia, ano 24 n. 2, 243-254, mai/ago. 2012 
Desde o início das atividades em 1977 até o ano de 2008, o Programa formou 317 Mestres em Geografia. Deste total, a maioria sempre atuou ativamente no mercado de trabalho estando, alguns já aposentados e, poucos iniciando a vida profissional. Dentre os que estavam ou estiveram no mercado de trabalho (289 pessoas), $52 \%$ atuava ou havia se aposentado no Ensino Superior Público enquanto 16\% estava ou se aposentou no Ensino Superior Particular, ou seja, $68 \%$ dos egressos, totalizando 196 pessoas, conforme representado na Figura 2.

Trabalhando em Institutos de Pesquisa encontravam-se 4\% e, em Empresas Privadas ligadas à área, 3\%. O Ensino Fundamental e Médio agrupava 67 egressos sendo 20\% no Ensino Público e 3\% em Escolas Particulares. É interessante destacar que um número reduzido de egressos do Programa estava atuando em outras ocupações não ligadas à área (apenas 2\%).

Dentre aqueles que ainda estavam no início da carreira profissional, 11 estavam cursando Doutorado, sendo 6 no próprio Programa da UNESP de Rio Claro e 5 em outras Universidades ( 3 no Brasil e 2 no exterior: Espanha e Suíça).

Do total estudado (317 egressos), foi possível localizar a maior parte ( $96 \%$ ); quanto aos $4 \%$ restantes : 4 faleceram, não se conseguiu nenhuma informação sobre apenas 5 pessoas e, dos 8 estrangeiros que cursaram o Mestrado, 3 retornaram aos países de origem. Tais números expressam a significância dos resultados alcançados por esta pesquisa sendo importante destacar que dos 317 egressos do Mestrado, à época, apenas 6 estavam sem emprego.

Figura 2. Áreas de atuação profissional dos egressos do mestrado do Programa de Pós-graduação em Geografia da UNESP Rio Claro - Período 1980-2008

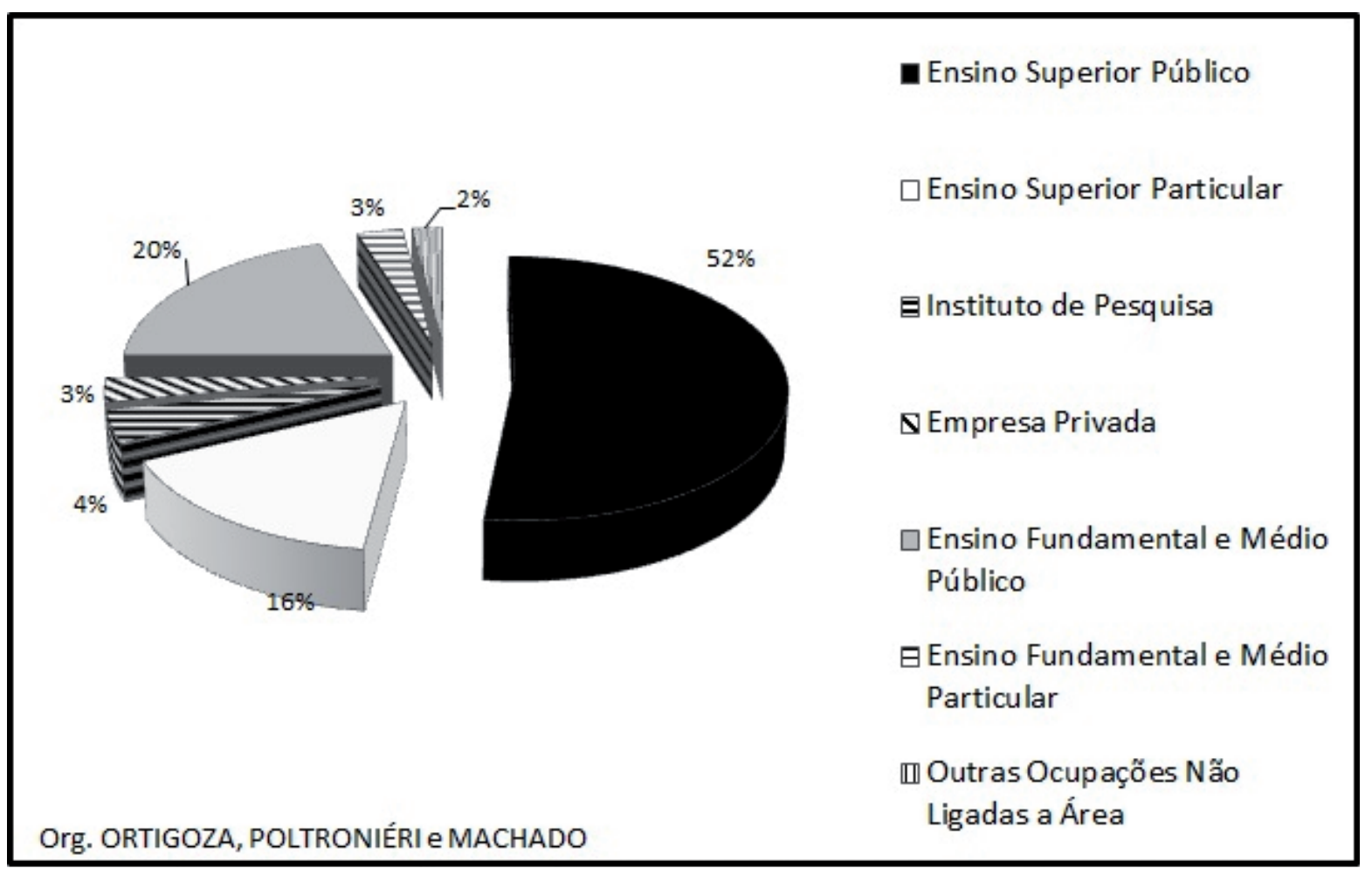

A espacialização do destino profissional dos egressos do Mestrado está resumida no mapa (Figura 3). Observa-se que em quase todos os estados da Federação havia profissionais formados pelo Programa de Pós-Graduação em Geografia de Rio Claro trabalhando na área, em vários setores,

Soc. \& Nat., Uberlândia, ano 24 n. 2, 243-254, mai/ago. 2012 
públicos e privados.

A maior concentração ocorria no Estado de São Paulo onde, em 51 cidades, havia profissionais formados pelo Programa; secundariamente apareciam os estados de Minas Gerais (11 cidades), Paraná (7 cidades), Rio Grande do Sul (4 cidades), Santa Catarina (3 cidades) e Mato Grosso do Sul ( 3 cidades). Nos outros estados havia representantes em uma ou duas cidades.

No exterior também havia egressos do Mestrado atuando profissionalmente; era o caso de Nova York e Washington D.C., nos Estados Unidos e de Melbourne, na Austrália, além dos estrangeiros que retornaram aos países de origem: Argentina e Moçambique.

Figura 3. Espacialização do destino profissional dos egressos do mestrado do Programa de Pós-graduação em Geografia da UNESP Rio Claro - Período 1980-2008

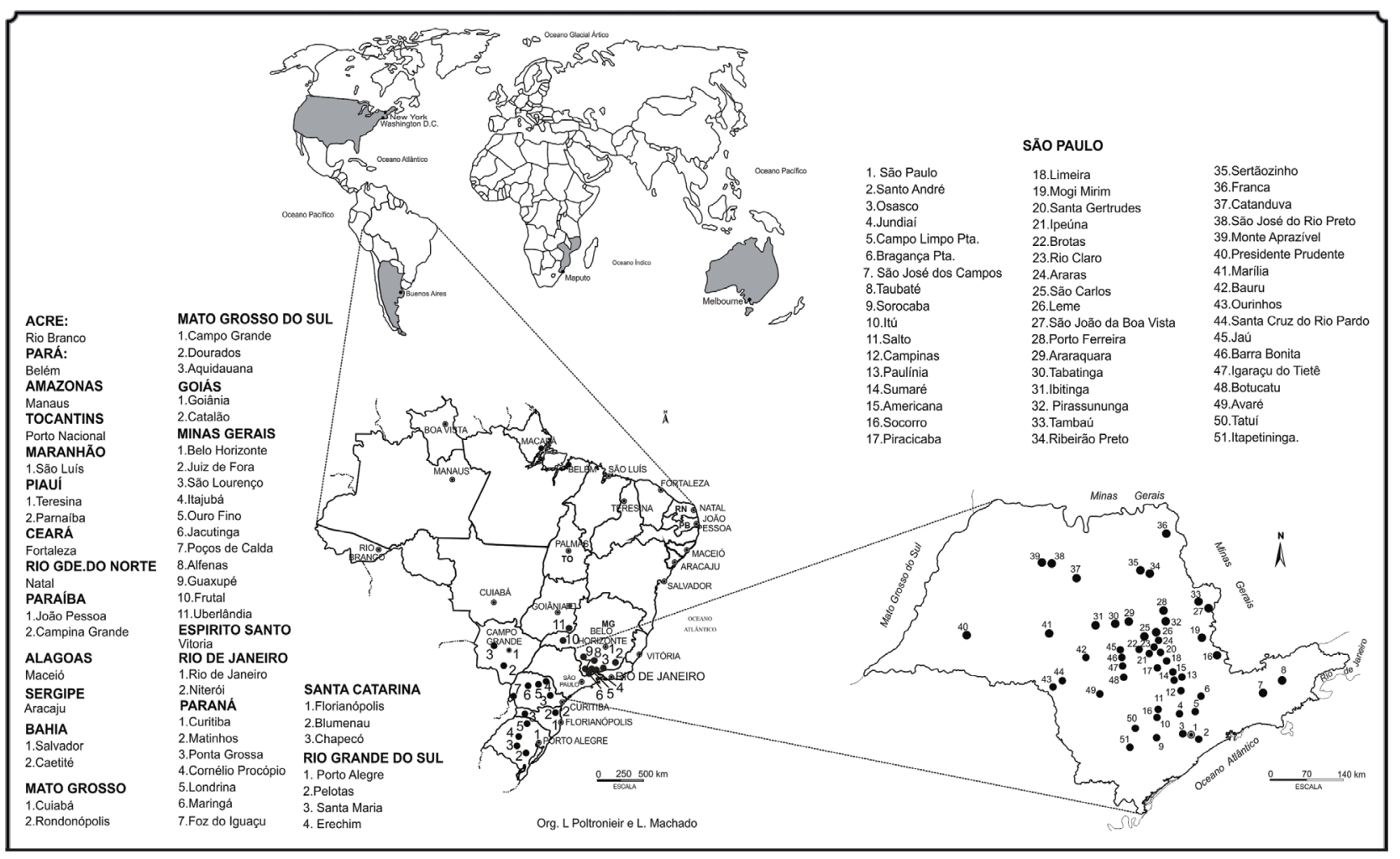

\section{EGRESSOS DO DOUTORADO}

Para o Doutorado, o período avaliado foi de 21 anos, uma vez que a primeira Defesa de Doutorado ocorreu em 1987, num total de 163 egressos. Dos alunos que procuraram o Programa para cursar o Doutorado no período 1987-2008, 30\% (49) eram formados no Curso de Geografia da UNESP de Rio
Claro, conforme os dados da Figura 4. O restante era proveniente de todas as regiões do Brasil, principalmente das regiões Sudeste (35\%), Nordeste (13\%), Sul (12\%), Centro-Oeste (5\%) e Norte (3\%). O Programa recebeu, também, 2 alunos estrangeiros provenientes da América Latina: Cuba(1) e México(1), totalizando $2 \%$. 
A atuação profissional dos egressos como importante dimensão no processo de avaliação de programas de pós-graduação Sílvia Aparecida Guarnieri Ortigoza, Lígia Celoria Poltroniéri, Lucy Marion C. Philadelpho Machado

Figura 4. Procedência dos egressos do doutorado do Programa de Pós-graduação em Geografia da UNESP Rio Claro - Período 1987-2008

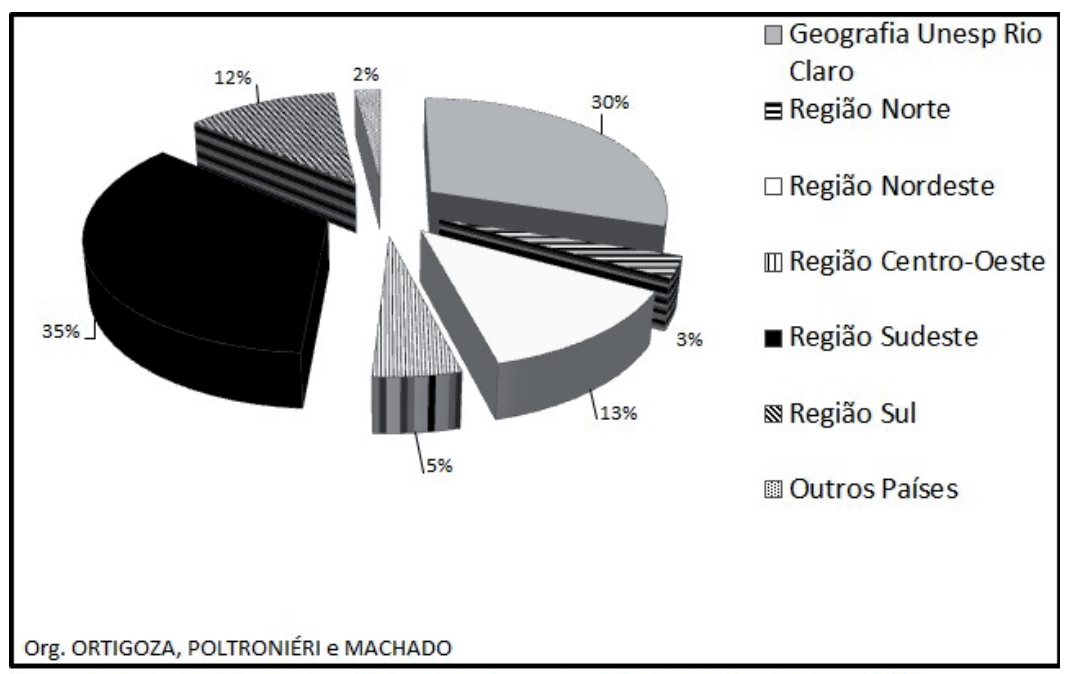

No Doutorado, no que se refere à atuação profissional dos egressos, observou-se que $74 \%$ atuava ou havia se aposentado no Ensino Superior Público enquanto $15 \%$ trabalhava ou havia se aposentado no Ensino Superior Particular, ou seja, 89\% dos egressos, totalizando 145 pessoas, conforme os dados da Figura 5.

Trabalhando em Institutos de Pesquisa encontravam-se 4 egressos (3\%) e em Empresas Privadas ligadas à área, também 3\%. O Ensino Fundamental e Médio Público contava com apenas 1 egresso do
Programa, enquanto poucos egressos do Doutorado estavam atuando em outras ocupações não ligadas à área (apenas 3\%).

No caso do Doutorado, os resultados obtidos são extremamente significativos, pois foi possível coletar as informações de todos os egressos (163); 3 faleceram ( $2 \%$ ) e os 2 estrangeiros retornaram aos países de origem. Ressalte-se que, dentre os egressos do Doutorado apenas 2 estavam, à época, sem emprego.

Figura 5. Áreas de atuação profissional dos egressos do doutorado do Programa de Pós-graduação em geografia da UNESP Rio Claro - Período 1987-2008.

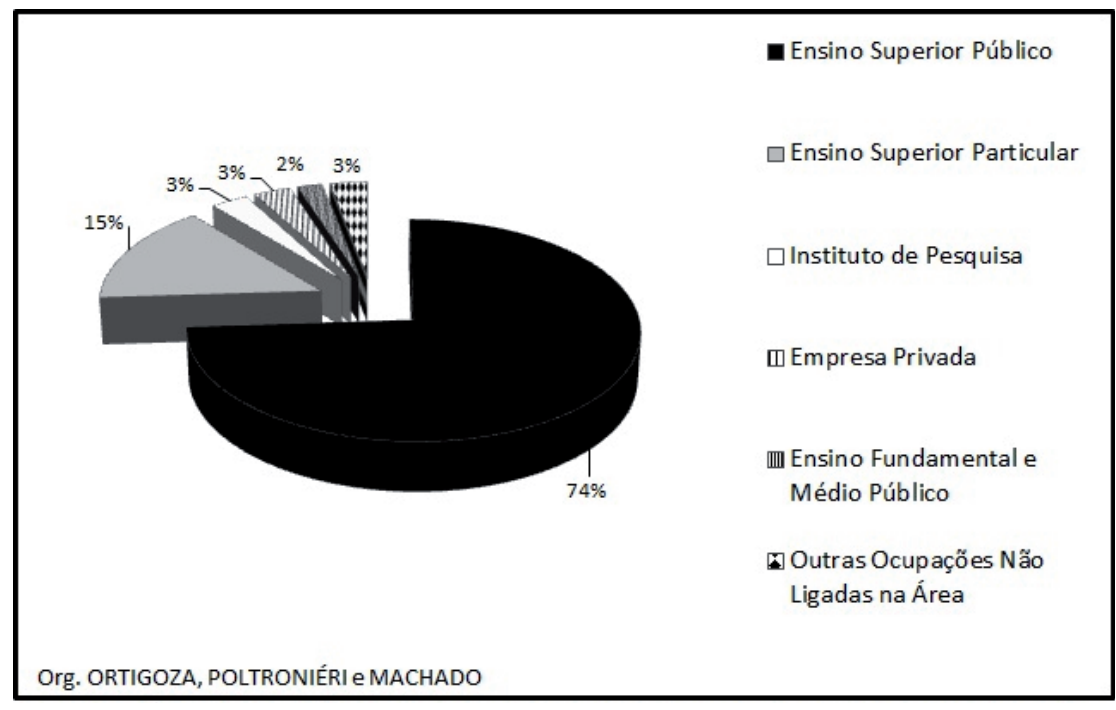

Soc. \& Nat., Uberlândia, ano 24 n. 2, 243-254, mai/ago. 2012 
A espacialização do destino profissional dos egressos do Doutorado está resumida na Figura 6. Observa-se que, assim como no Mestrado, na grande maioria dos estados da Federação havia profissionais formados pelo Programa de Pós-Graduação em Geografia de Rio Claro, atuando na área, em vários setores públicos e privados.

A maior concentração ocorria no Estado de São Paulo onde, em 23 cidades, havia profissionais formados pelo Programa; secundariamente apareciam os estados de Minas Gerais (6 cidades), Mato Grosso do Sul (4 cidades), Rio Grande do Sul (4 cidades), Paraná (3 cidades), Goiás (3 cidades) e Bahia (3 cidades). Nos outros estados havia representantes em uma ou duas cidades. Em Cuba (Havana) e no México (Cidade do México), os estrangeiros egressos do Programa também estavam atuando profissionalmente.

Figura 6. Espacialização do destino profissional dos egressos do doutorado do Programa de Pós-graduação em Geografia da UNESP Rio Claro - Período 1987-2008

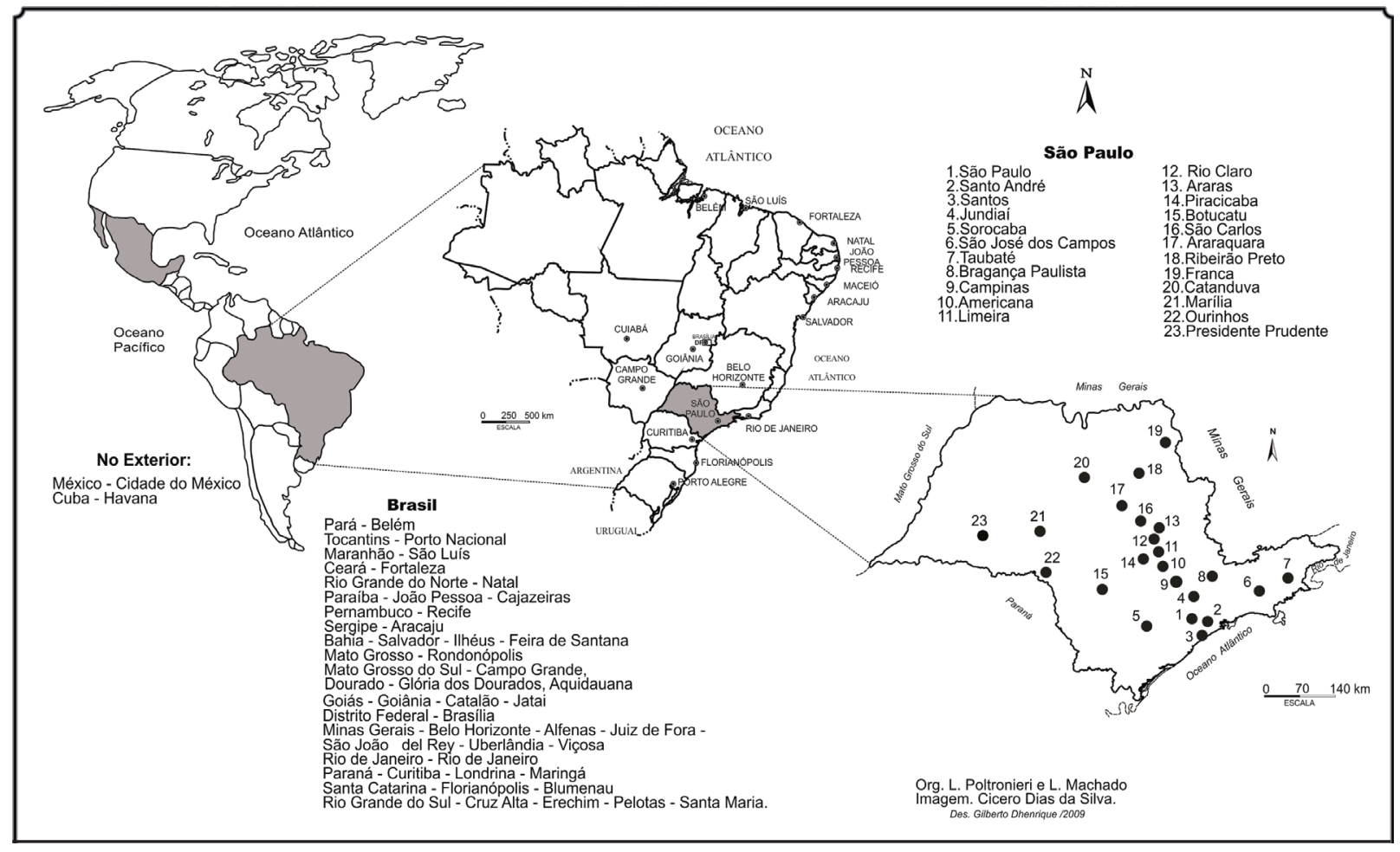

\section{CONCLUSÃO}

A realização desta pesquisa permitiu que se comprovasse a importância dos egressos do Programa como agentes formadores nas várias regiões do país e, até mesmo, no exterior. E, sem sombra de dúvida, os resultados obtidos comprovam que a análise da atuação profissional dos egressos é, realmente, uma dimensão importante no processo de avaliação dos Programas de Pós-Graduação.
Com base neste levantamento foi possível ressaltar que, no período analisado, ou seja, em 31 anos de formação de Mestres em Geografia (1977-2008) e 25 anos de formação de Doutores em Geografia (1983-2008) o Programa de Pós-Graduação da UNESP de Rio Claro apresenta resultados extremamente positivos quando se considera a atuação profissional dos egressos.

A grande maioria estava trabalhando ou já se aposentou, atuando no Ensino Superior Público e ou 
Particular: 68\% dos Mestres e 89\% dos Doutores os quais, em todas as regiões do país, têm contribuído para a formação de outros profissionais, tanto em nível de Graduação como de Pós-Graduação.

Além disso, constatou-se que um grande número de egressos ocupava, ou já ocupou, altos cargos de Direção, Chefia e Coordenação tanto em Universidades Estaduais como Federais e Particulares, muitas vezes, atuando na implantação de novos Cursos de Graduação e ou de Pós-Graduação.

Apesar do grande esforço despendido na coleta, organização e tratamento quantitativo das informações sobre os egressos, têm-se consciência de que apenas uma parte inicial da avaliação foi completada. Dois aspectos são fundamentais para que este levantamento pioneiro tenha continuidade:

- em primeiro lugar, a construção de instrumentos que passem a fornecer, sistematicamente, os dados, facilitando a coleta, como por exemplo: ficha que o concluinte deve preencher no ato da entrega da Dissertação ou Tese para atualizar suas informações; e, em segundo lugar, há necessidade de criar, nos egressos, uma cultura de valorização das informações sobre sua atuação profissional pós-titulação, tendo em vista a importância que a Comissão de Avaliação da CAPES atribui a este item. É também oportuno que o egresso informe, com regularidade e precisão, os dados relativos à sua produção intelectual.

Os grandes entraves para a realização desta pesquisa foram a falta de comunicação entre o egresso e o ex-orientador e com o Programa de modo geral, aliado ao desinteresse do egresso, em alguns casos, em manter atualizadas as informações da Plataforma LATTES. Mas, apesar disso, a metodologia empregada para a análise da procedência e atuação profissional dos egressos do Programa de Pós- Graduação em Geografia da UNESP de Rio Claro revelou-se extremamente eficaz e pode ser utilizada por qualquer Programa de Pós-Graduação, com as devidas adaptações, para avaliar tanto sua qualidade como sua extensão. Para o Programa, a compilação dessas informações e a análise e mapeamento dos resultados representou um importante legado que permitiu a revelação da importância de sua formação e nucleação em nível nacional e internacional.

A divulgação desta metodologia e os resulta- dos obtidos certamente estimularão novas pesquisas por outros Programas visando à construção de diálogo positivo para o futuro das avaliações nos âmbitos dos Programas de Pós-Graduação.

Neste estudo de caso ficou confirmada a importância do Programa no quesito nucleação, tão valorizado pela CAPES. Os resultados obtidos reafirmaram que o Programa de Pós-Graduação em Geografia- Área de Concentração em Organização do Espaço da UNESP de Rio Claro instalado em 1976 está totalmente consolidado e é um importante elemento no desenvolvimento e disseminação da ciência geográfica no Brasil e no exterior.

\section{REFERÊNCIAS}

CUNHA, I. C. K. O. et al Construindo Instrumentos de Avaliação para os Cursos de Pós-Graduação Lato Sensu da UNIFESP: relato de experiência. Estudo em Avaliação Educacional, v. 18, n. 38, set/dez. 2007.

CARLOS, A. F. A. Questões para a construção de uma política de pós-graduação em geografia. Revista da ANPEGE, Curitiba, ano 1, $\mathrm{n}^{\circ} 1,2003$.

DIAS SOBRINHO, J. e RISTOFF, D. (org) Universidade Desconstruída. Florianópolis: Insular, 2000.

DUARTE, G. M. A pesquisa e a Pós-Graduação em Geografia no Brasil - Os dez anos da ANPEGE. Revista da ANPEGE ano 1, n 1 Curitiba, PR 2003.

GERARDI, L. H de O. ANPEGE: O resgate de uma história. Revista da ANPEGE, Curitiba, ano 1, $\mathrm{n}^{\circ} 1$, 2003.

MENDONÇA, F. Temas, Tendências e Desafios da Geografia na Pós-Graduação Brasileira. Revista da ANPEGE, Fortaleza, ano 2, $\mathrm{n}^{\circ} 2,2005$.

SILVA, J. B. e DANTAS, E. W. C. A pós-graduação em Geografia no Brasil: uma contribuição à política de avaliação. Revista ANPEGE, São Paulo, 2005.

SUERTEGARAY, D. M. A. A expansão da pós-graduação em Geografia no Brasil e a ANPEGE. Revista

Soc. \& Nat., Uberlândia, ano 24 n. 2, 243-254, mai/ago. 2012 
da ANPEGE, Paraná, ano1, n¹, 2003.

SUERTEGARAY, D. M. A. O atual e as tendências do ensino e da pesquisa em Geografia no Brasil. Revista do Departamento de Geografia (USP), São Paulo, v.16, p.38-45, 2005.

SUERTEGARAY, D. M. A. Rumos e Rumores da Pós- Graduação e da Pesquisa em Geografia no Brasil. Revista da ANPEGE. V.3, p.17-31, 2007.

SILVA, J.B e OLIVEIRA, M. P. A trajetória da pós-graduação no Brasil e a ANPEGE: Algumas questões sociais. Revista da ANPEGE, v.5, p.106-122, 2009. 